\title{
Development of Bis-GMA-free biopolymer to avoid estrogenicity
} (1)

\section{Abstract}

Objective. Although bisphenol A-glycidyl methacrylate (Bis-GMA)-based dental materials are widely used in dentistry, Estrogenicity from released bisphenol A remains a concern due to possibility of adversely affecting the growth of children and homeostasis of adults. Here, a new family of isosorbide-derived biomonomers were synthesized and experimentally utilized as a matrix of dental sealants to provide physico-mechanical and biological properties comparable to those of a conventional Bis-GMA-based material but without the the potential estrogenicity.

Methods. After synthesis of isosorbide-derived biomonomers (ISDB) by light polymerization, an experimental dental sealant with different silica filler concentrations $(0 \sim 15 \mathrm{wt} \%)$ was characterized and compared to a commercially available Bis-GMA-based sealant. Cytotoxicity and estrogenicity assays were conducted with human oral keratinocytes and estrogen-sensitive MCF-7 cells, respectively.

Results. ISDB-based dental sealants exhibited typical initially smooth surfaces with depth of cure, Vickers hardness, compressive strength/modulus, water resorption/solubility, and flowability comparable to those of the commercial sealant and met the ISO standard for dental sealants and polymer-based restorative materials. Indirect cytotoxicity tests using an extract showed comparable viability among experimental ISDB-based materials and a commercial Bis-GMA-incorporated control. DNA synthesis in MCF-7 cells (a marker of estrogenicity) and the release of bisphenol A under enzymatic incubation were not detected in ISDB-based materials.

Significance. In conclusion, the comparable physico-mechanical properties of ISDB-based materials with their cytocompatibility and lack of estrogenicity suggest the potential 
1 usefulness of ISDBs as a newly developed and safe biomaterial.

2 Keywords: isosorbide-derived biomonomer; experimental biopolymer; estrogenicity; 3 cytocompatibility; bisphenol free

4 
1

2

3

4

5

6

7

\section{Introduction}

Estrogenicity is caused by a number of synthetic compounds that mimic the physiological activity of estrogen and adversely affects the development of children and hormone homeostasis in adults[1-3]. One out of many synthetic compounds that induce estrogenicity is

bisphenol A (BPA), a molecule known to be a core component of Bis-GMA (BPA glycidylmethacrylate), which is the basis of dental restorative composites[4,5]. BPA mimics the estrogen hormone; this is the reason why it is considered as an endocrine disruptor [6]. BPA is potentially released from Bis-GMA-based dental materials, mainly due to incomplete photopolymerization or impurity (i.e. BPA or BIS-GMA) inclusion, which are hydrolytically or biologically degraded into BPA [7]. Thus, BPA and/or its derivatives are possibly released into the oral cavity and might induce unexpected estrogenic effects[8,9], even though BPA is released from Bis-GMA at a low level under in vitro conditions[10]. Overall, health concerns with respect to Bis-GMA and its related products remain, since they contain the BPA moiety within their chemical structure, which cannot be ruled out that emergence of estrogenic BPA occur [9].

Many trials have been performed to replace Bis-GMA monomers in dentistry by $2,2,4,4-$ tetramethyl-1,3-cyclobutanediol, urethane dimethacrylate, bile acids, and isosorbide itself to reduce possible adverse health issues from BPA[11], but optimal Bis-GMA-free composite systems have not been successfully explored majorly due to lack of physico-mechanical properties. Isosorbide based checmial compounds have been highlighted as possible replacement or supplemented biomonomer in biopolymer complexes due to its safe origin (bioderived from starch glucose), high mechanical strength, biodegradability and biocompatibility, classified by Food and Drug Administration of the United States Government as 'generally recognized as safe' [12-17]. Although isosorbides have a bicyclic 
1 chemical structure, which is similar to BPA, and are susceptible to hydrolysis or enzymatic

2 degradation as biodegradable materials, they and their derivatives are considered as safe

3 materials due to their natural origin and eco-friendly characteristics, in contrast to the

4 petrochemically derived Bis-GMA $[12,18,19]$. However, to the best of our knowledge, the

5 investigation about the estrogenicity, after optimal fabrication of isosorbide-based materials

6 comparable to commercially available medical products in terms of mechanical and

7 biological properties, has not been investigated.

8 Thus, the aims of this study are the development of isosorbide based monomers, the 9 compositional optimization of them, for application in dental sealant as an examplar medical 10 product with physico-mechanical properties similar to those of Bis-GMA-based materials, and the investigation of estrogenicity from them under enzymatic degradation. Initially, a new synthesis of light polymerizable isosorbide-derived biomonomers (ISDBs) was performed, and the possible byproducts resulting from ISDB-based dental sealant degradation were investigated under enzymatically accelerated hydrolysis to confirm the absence of BPArelated byproducts, which would cause estrogenicity. Furthermore, the physico-mechanical properties and in vitro cytocompatibility/estrogenicity of these materials were determined with a commercial Bis-GMA-based counterpart. The major null hypothesis of this investigationis is that there is difference in myriad properties such as physico-mechanical properties and in vitro cytocompatibility/estrogenicity between commercial Bis-GMA based dental sealant and developed ISDB-based dental sealant. 


\section{$1 \quad$ Materials and Methods}

Materials

1,4:3,6-Dianhydro-D-sorbitol (isosorbide, 98\%), ethylene carbonate (99\%), triethylene glycol dimethacrylate (TEGDMA, 95\%), dibutyltin dilaurate (DBTDL, 95\%), 2-isocyanatoethyl methacrylate (IEM, 98\%), camphorquinone (CQ, 97\%), and ethyl 4-dimethylaminobenzoate (EDMAB, 99\%) were obtained from Sigma-Aldrich (St Louis, MO, USA) and distilled to remove inhibitors and increase purity. Potassium carbonate (99.5\%), ethyl acetate $(99.5 \%), n$ hexane (99.5\%), methanol (99.5\%), and chloroform (99.5\%) were supplied by Daejung Chem. Co. Ltd. (Seoul, Korea).

${ }^{1} \mathrm{H}$ nuclear magnetic resonance (NMR) spectra were recorded with an AVANCE III HD 850 spectrometer (850 MHz, Bruker, Germany) and $\mathrm{CDCl}_{3}$ as a solvent. All data are given in terms of chemical shift $(\delta, \mathrm{ppm})$ downfield from tetramethylsilane. High-resolution mass spectra were recorded using a JMS-700 spectrometer (JEOL, JAPAN) in positive ionization mode. Elemental analysis was performed using a Flash 2000 (Thermo Fisher Scientific, Waltham, MA, USA) elemental analyser.

\section{Fabrication of isosorbide-derived biomonomer}

Details of the synthesis are given in the appendix, which are in-house fabricated for the first time. Briefly, isosorbide-derived biomonomer was synthesized into an intermediate chemical compound (bis(2-hydroxyethyl) isosorbide, BHIS) and then to a final monomer (ISDB). The ISDB isosorbide was synthesized according to the manufacturer's procedures (SigmaAldrich). Briefly, isosorbide sequentially reacted with ethylene carbonate, potassium carbonate, and IEM to make isosorbide-derived biomonomers. Fig. 1A presents the sequential synthesis of BHIS and the ISDB, which was finally prepared by a urethane 
coupling reaction between the hydroxyl group of BHIS and the isocyanate group of IEM, making ethylene glycol linkages. The isosorbide core acts as a rigid segment, and the ethylene glycol and urethane groups on both sides of the isosorbide core were added for elasticity (less brittle) and to reinforce the mechanical properties by hydrogen bonding, potentially giving more toughness. Both termini of ISDB have polymerizable methacrylate groups to crosslink other methacrylates. Hydrolysis of ISDB ester bonds under esterase generated the degradation product of isosorbide-ethylene glycol, not bisphenol A, meaning less concerns about estrogenicity from estrogen mimicking structure like Bisphenol A (Fig. 1B). The yield of BHIS and ISDB synthesis was $67 \%$ and $91 \%$ respectively. Detail methodology of synthesis was given in supplementary file.

* ISDB: (((3R,3aR,6S,6aR)-hexahydrofuro[3,2-b]furan-3,6-diyl)bis(oxy))bis(ethane-2,1-diyl) bis((4-methyl-3-oxopent-4-en-1-yl)carbamate)

\section{Measurement of viscosity}

The viscosity of the ISBD was measured by means of a viscometer (DV 2T, Brookfield, Massachusetts, USA) and compared with other monomers: Bis-GMA and TEGDMA. For the viscosity measurements, the samples were placed directly on the plate and the measurement was carried out in a dark room at $25^{\circ} \mathrm{C}$ at a shear rate range of 0 to $50 \mathrm{rpm}$.

\section{Fabrication of dental sealant}

Commercially available dental sealant (Concise, 3M) consists of 2 kinds of matrix resin monomers (Bis-GMA and TEGDMA) and was chosen as the control material. The synthesized ISDB was used instead of Bis-GMA. The synthesized ISDB was mixed with TEGDMA as an inert diluent and CQ and EDMAB as photoinitiators. The ratio among ISDB, 
1 TEGDMA, CQ, and EDMAB was 29.5:69.5:0.5:0.5 (wt\%). Silanated silica microparticles

2 (Polysciences, Warrington, PA, USA) were added in quantities of 1, 5, 10 or $15 \mathrm{wt} \%$ relative

3 to the total amount of experimental dental sealant, partially replacing the ISDB to optimize

4 the physico-mechanical properties comparable to commercial one (Fig. 1C). Amounts of

5 filler were determined based on filler contents from other sealant materials. 4-

6 (dimethylamino)-benzene ethanol was used for photoinitiator for the commercial dental

7 sealant. An LED curing light gun (Litex 695, Dentamerica Industry, $1000 \pm 56 \mathrm{~mW} / \mathrm{cm}_{2}$ ) was

8 used for polymerization. Example of application with experimental and commercial dental

9 sealant applied to tooth groove was shown (Fig. 1D). Details are given in the appendix. 


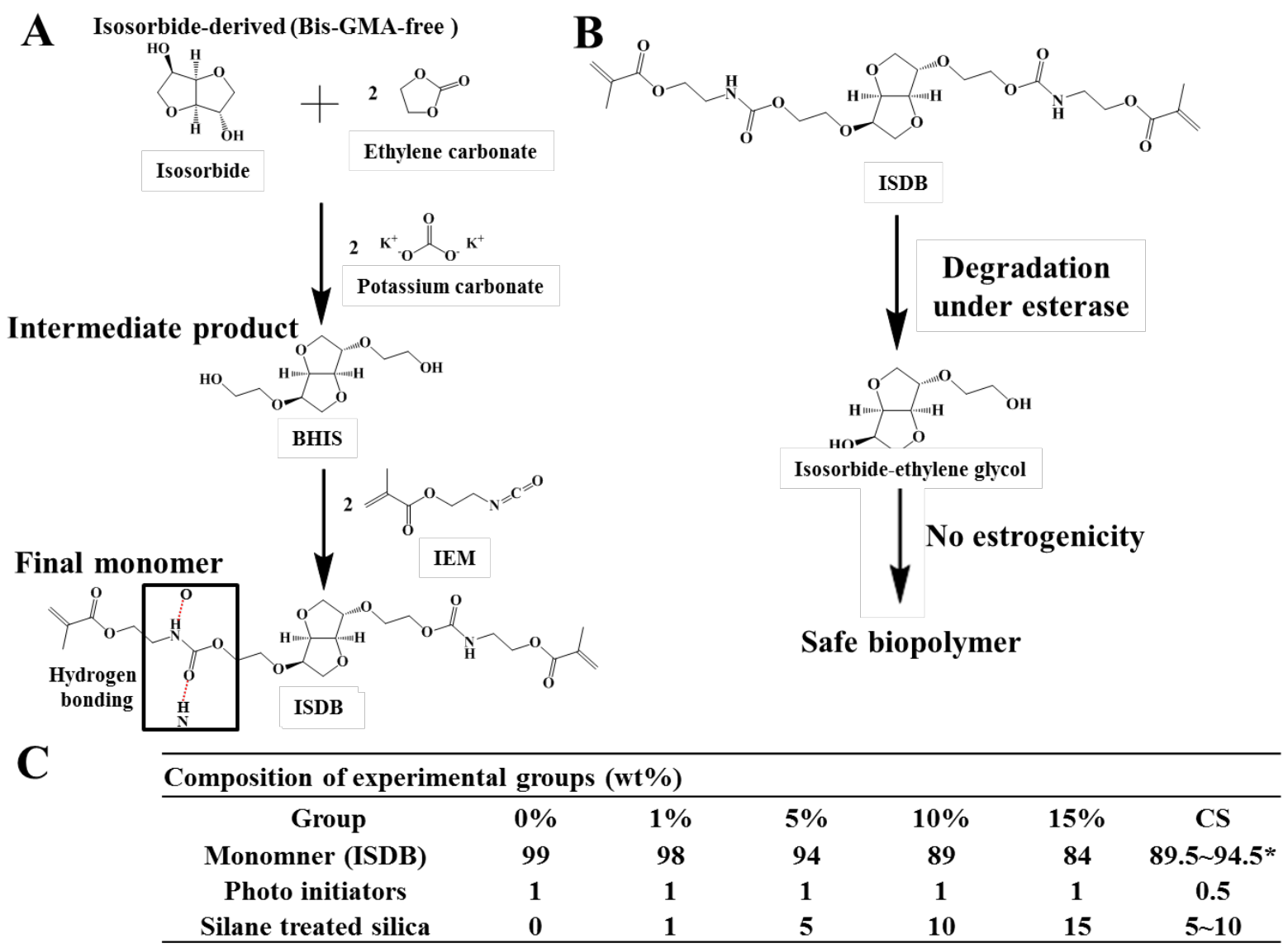

* Triethylene glycol dimethacrylate and BIS-GMA

D
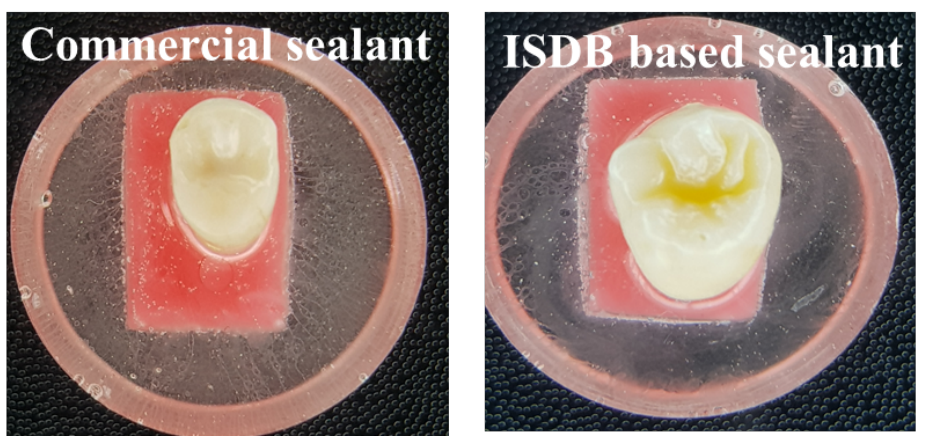

Figure 1. Synthesis of isosorbide-derived biomonomers (ISDBs) for dental restorative materials and experiments in this study. (A) Structure of the starting monomer, intermediate product, and final monomer. (B) Hydrolysis of ISDB ester bonds under esterase generated the degradation product of isosorbide-ethylene glycol, not bisphenol A. (C) Composition of experimental groups. (D) Application of Bis-GMA based commercially available or ISDBs based Bis-GMA-free biopolymer to tooth groove as dental sealant.

\section{Degradation products from dental sealant}

Photopolymerized ISDB based dental sealant ( $h=1 \mathrm{~mm}$ and $\phi=15 \mathrm{~mm}$ for $40 \mathrm{~s}$ on each side) were aged in deionized water $\left(\mathrm{DW}, 3 \mathrm{~cm}^{2} / \mathrm{mL}\right.$ ) for 2 weeks at $37{ }^{\circ} \mathrm{C}$ with $10 \mathrm{mg} / \mathrm{mL}$ porcine 
esterases (Sigma, $>15$ units/mg) to mimic biological hydrolysis by enzymes in saliva. The degradation products that were in the water were extracted into ethyl acetate and washed with distilled water three times. The organic layer was dried and evaporated in a vacuum oven at $60{ }^{\circ} \mathrm{C}$ for $24 \mathrm{hr}$ to remove ethyl acetate. The dry extract was mixed with methylene chloride and analysed by a gas chromatograph mass spectrometer (GC/MS, TSQ 8000 Evo, Thermo Fisher Scientific) system.

\section{Physciomechanical characteristics of dental sealant}

For evaluating experimental dental sealant compared to commercial product, physicochemical characteristics such as depth of cure, water resorption andsolubility, and compressive strength were investigated. First, the depth of cure and water resorption and solubility ( $\mathrm{n}=5$ ) were investigated according to ISO standard 6874 (depth of cure) and 4049 (water resorption and solubility) [20,21]. For depth of cure, after $40 \mathrm{~s}$ of light-curing the top of dental sealant in a stainless steel mould $(h=6 \mathrm{~mm}$ and $\phi=4 \mathrm{~mm})$ and removing the uncured material with the plastic spatula, the height of the polymerized materials was measured with a micrometer, and half of the measured height was determined as the depth of cure. A water resorption and solubility test was performed with a polymerized specimen $(h=$ $1 \mathrm{~mm}$ and $\phi=15 \mathrm{~mm}$ ). Briefly, after mold was filled with dental sealant, light-curing was performed by overlapping irradiation method (5 times x 40 s per each exposure). After $24 \mathrm{hr}$ incubation in desicators at $37^{\circ} \mathrm{C}$, dry weight was measured as $\mathrm{ml}(\mathrm{mg})$. Then, specimens were immersed in water for $7 \mathrm{~d}$ at $37{ }^{\circ} \mathrm{C}$. When the removed specimen was dried until free from visible moisture, weight was measured as $\mathrm{m} 2 \mathrm{(mg})$. Finally, after fully drying of specimen under desiccators to have costant mass, $\mathrm{m} 3(\mathrm{mg})$ was detected. Water resorption was determined by $(\mathrm{m} 2-\mathrm{m} 3) / \mathrm{V}\left(\mathrm{V}\right.$ is the volume of the specimen, $\left.\mathrm{mm}^{3}\right)$. Water solubility was 
2 Next, for compressive testing, specimens $(\mathrm{n}=10)$ were produced using a stainless steel mould

calculated by (m1-m3)/V. ( $h=6 \mathrm{~mm}$ and $\phi=4 \mathrm{~mm}$ ) according to an ISO standard 9917-1 [22] and exposed to LED light for $40 \mathrm{~s}$ on each side. After considering the above physical properties, $0 \%$ and $15 \%$ samples were chosen for mechanical testing. Prepared bar specimens were positioned on an Instron 8871 machine (MA, USA) with a $10,000 \mathrm{~N}$ load cell at a crosshead speed of 1.0 $\mathrm{mm} / \mathrm{min}$ [23]. The Vickers hardness (HM-221, Mitutoyo, Tokyo, Japan) was measured with $300 \mathrm{gf}(2.94 \mathrm{~N})$ for $20 \mathrm{~s}$ in three different spots on each specimen, and these values were averaged $(n=10)$. Lastly, flowability was measured using 20,50 , or $75 \mu \mathrm{m}$ wide grooves, replicated in silicon mold using metal apparatus for reproduction of detail (ISO 6873 for dental gypsum). After filling above each groove, resin-silicon was perpendicularly sectioned and investigated by optical microscope to check filling ability. Continuous contact between resin and grooves were optically investigated and continuous contact was marked as characteristics of successful flowability.

\section{Surface characteristics of dental sealant}

The surface of the specimens were analyzed using scanning electron microscopy (SEM, Sigma 500; ZEISS, Oberkochen, Germany) and and surface profiler ( $\mathrm{n}=10$, Ra, SJ-400, Mitutoyo, Japan) respectively as described in detail elsewhere [24-26].

\section{Cytotoxicity test}

Immortalized human oral keratinocytes (IHOKs) were used in this study [27]. A cytotoxicity test was performed based on an ISO standard [28]. After cells were seeded $\left(1 \times 10^{4}\right.$ cells/ $96-$ well plate) and incubated at $37{ }^{\circ} \mathrm{C}$ in a humidified atmosphere of $5 \% \mathrm{CO}_{2}$ and $95 \%$ air, one 
1 part of the extract from the specimens was added into one part of Dulbecco's modified eagle

2 medium/nutrient mixture f-12 (3:1) (DMEM/F-12(3:1)) supplemented with $10 \%$ foetal

3 bovine serum (FBS), penicillin (100 units/ml), and streptomycin $(100 \mu \mathrm{g} / \mathrm{ml})$. Extracts of 4 specimen $(h=1 \mathrm{~mm}$ and $\phi=15 \mathrm{~mm})$ were obtained at a ratio of $3 \mathrm{~cm}^{2} / \mathrm{mL}$ for $24 \mathrm{hr}$ at $37^{\circ} \mathrm{C}$ 5 in a shaking incubator $(120 \mathrm{rpm})$ using supplemented media following the recommendations 6 of ISO 10993-12 [29]. After $24 \mathrm{hr}$ of incubation, a water-soluble tetrazolium salt (WST) 7 assay was performed according to previously described methods using light with a wavelength of $450 \mathrm{~nm}(\mathrm{n}=6)$ [30]. Live (green colored) and dead (red colored) staininng assay (Thermo Fisher Scientific) was performed according to manufacturer's instruction to confirm above WST assay.

\section{Estrogenicity assay}

Estrogenicity was investigated by quantifying newly synthesized DNA of human MCF7, an established estrogenic cell line endogenously expressing estrogenic receptor $\alpha$, for $24 \mathrm{hr}$ using nucleoside analogue bromo-deoxyuridine (BrdU) and Click-iT ${ }^{\mathrm{TM}}$ Plus EdU Flow Cytometry Assay Kits (Thermo Fisher Scientific) according to modified procedures [31]. MCF-7 was cultured in DMEM supplemented with 10\% FBS and 1\% penicillin-streptomycin (PS) at $37{ }^{\circ} \mathrm{C}$ in an atmosphere of $5 \% \mathrm{CO}_{2}$ and $95 \%$ air under saturating humidity. MCF-7 cells were seeded in 24 -well plates to an initial concentration of 20,000 cells per well in DMEM with $10 \%$ FBS and 1\% PS (1 mL/well). After $24 \mathrm{hr}$ of cell adhesion, the cells were washed with phosphate-buffered saline (PBS), and the culture medium was changed to DMEM supplemented with 10\% synthetic knockout serum replacement (growth factor and steroid-free) [32] and 1\% PS without phenol red, consisting of $200 \mathrm{mM}$ L-glutamine, $1 \mathrm{M}$ hydroxyethyl piperazineethanesulfonic acid (HEPES) buffer, $100 \mathrm{mM}$ sodium pyruvate and 1\% 
1 of $10 \mathrm{mg} / \mathrm{mL}$ penicillin-streptomycin (refer to supplemented steroid-free media). Extract from

2 each specimen in cell culture medium supplemented with steroid-free at a ratio of $3 \mathrm{~cm}^{2} / \mathrm{mL}$

3 was added to MCF-7, and the samples were cultured for the next 72 hrs. Extract was

4 performed at $37{ }^{\circ} \mathrm{C}$ for $24 \mathrm{hr}$ under shaking condition (180 rpm). Positive and negative

5 controls were $1 \times 10^{-8}$ M 17- $\beta$-estradiol (Sigma) and $10 \mathrm{nM}$ bisphenol A (Sigma), and steroid-

6 free medium, respectively. Fluorescence-activated cell sorting (FACS) was performed

7 according to the manufacturer's protocol. Briefly, BrdU-treated cells were fixed,

8 permeabilized, and then labelled with fluorescein. A FACS Calibur flow cytometer (BD

9 Biosciences, San Jose, CA, USA) with excitation/emission wavelengths of 408/530 nm was

10 used for analysis. Data for 10,000 cells in each sample $(n=3)$ were analysed by CellQuest

11 Pro software (v.5.1 BD Biosciences).

\section{Statistical analysis}

14 The data are expressed as the mean \pm SD of at least three independent experiments.

15 Statistical significance was evaluated by a one-way analysis of variance with a Tukey post hoc test using SPSS (Version 21.0; SPSS, Chicago, IL) when the equality of variance among groups was met. When equality of variance among groups was not satisfied, Welch test with

Dunnett's T3 as post hoc test was used. A value of $P<0.05$ was considered statistically significant. 


\section{Results}

\section{Characterization of isosorbide-derived biomonomer}

3 Light-curable ISDBs have been newly synthesized to replace the BPA-based Bis-GMA.

4 Viscocity of ISDB was measured as $2.42 \mathrm{~Pa} \cdot \mathrm{s}$ while that of Bis-GMA and TEGDMA was 473

5 and $0.01 \mathrm{~Pa} \cdot \mathrm{s}$ respectively under the same conditions. After ISDB was purified by column 6 chromatography, it was chemically-characterized by ${ }^{1} \mathrm{H}$ NMR spectrometer, a mass

7 spectrometer, and an elemental analyser, presenting the designed chemical structure of BHIS 8 and ISDB (Appendix Fig. 1). After the experimental dental sealant was combined with 9 TEGDMA (matrix) and CQ/EDMAB (photo-initiator) to form a model dental restorative material, light-curable polymerization was checked by FT-IR, which revealed a decrease in $\mathrm{C}=\mathrm{C}\left(1637 \mathrm{~cm}^{-1}\right)$ content over the light curing time (Appendix Fig. 2). Finally, we used GC/MS to determine the possible chemical degradation products of the ISDB-based dental sealant material. Set dental sealant without any filler was aged for 2 weeks in water with enzyme (porcine liver esterase, $10 \mathrm{mg} / \mathrm{mL}$ ) to mimic the enzymatic hydrolysis in saliva. 2 weeks incubation of specimen with high concentration of esterase was used as an accelerated degradation condition, resulting in severe degradation of biopolymer due to their hydrolysing capacity against the ester bonds of polymer, which is a major mechanism for biopolymer enzymatic depolymerisation in vivo condition [33]. Isosorbide derivatives, including an ethylene glycol derivative ((3R,3a $R, 6 S, 6 \mathrm{a} R)$-6-(2-hydroxyethoxy)hexahydrofuro[3,2-b]furan3-ol (isosorbide-ethylene glycol)), were detected and have not been identified as estrogenicity inducers so far (Appendix Fig. 3). The peaks at 2.39 and $5.82 \mathrm{~min}$ in the GC chromatogram and their corresponding mass spectrum peaks (maxima at 193.23 and 192.62) corresponded to the molecular weight $(\sim 193)$ of isosorbide-ethylene glycol and its isomer (Fig. 1B). 
A
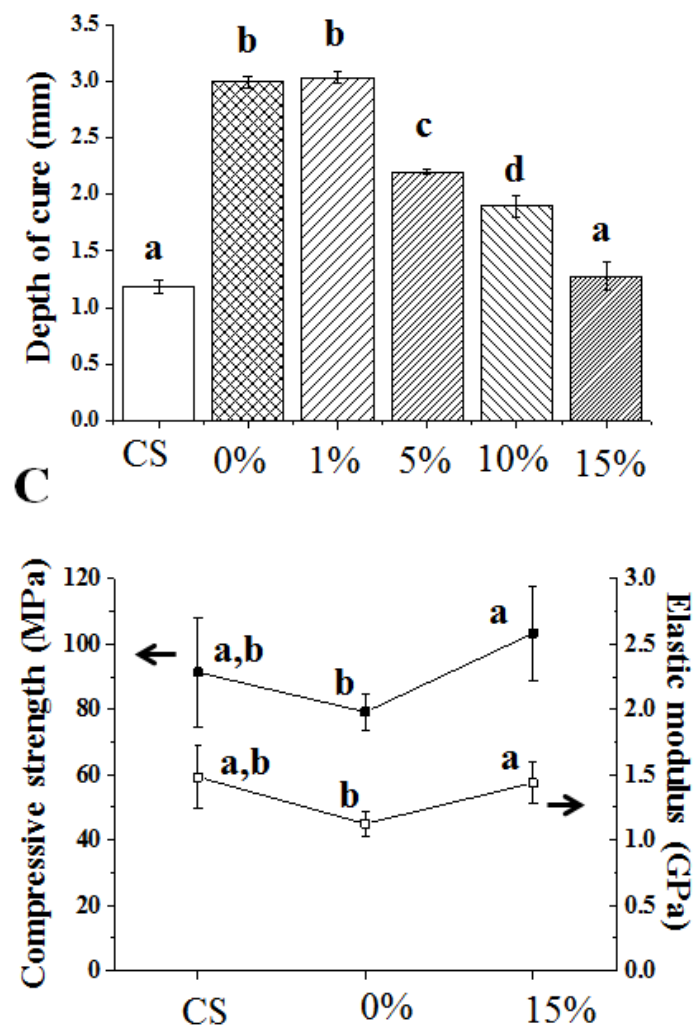

B

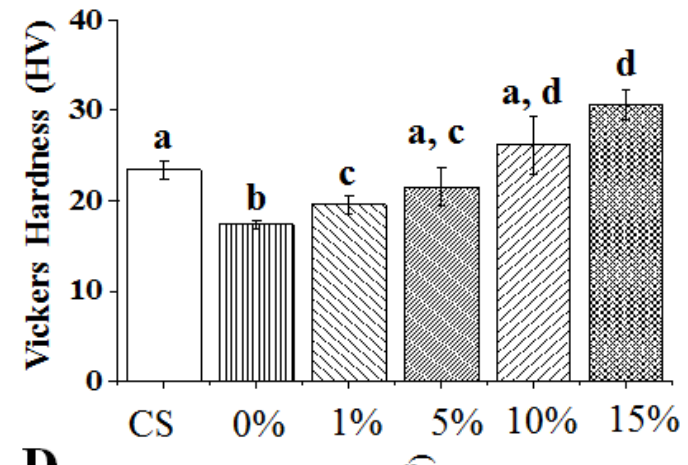

D

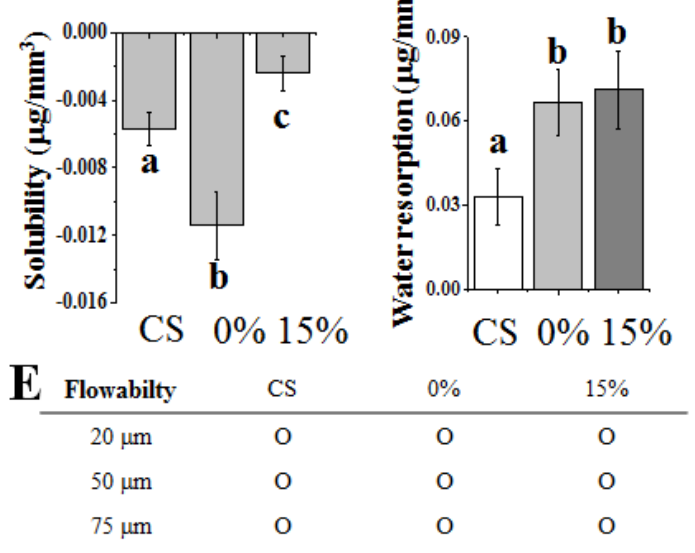

Figure 2. Physico-chemical properties of ISDB-based dental materials. (A) Depth of cure $(\mathrm{n}=5),(B)$ Vickers hardness $(\mathrm{n}=10),(\mathrm{C})$ compressive strength and modulus $(\mathrm{n}=10)$, (D) water solubility/resorption $(n=5)$, and (E) flowability into 25,50 and $75 \mu \mathrm{m}$ gaps $(n=5)$. Different letters indicate statistically significant differences between their corresponding values $(P<$ $0.05)$. CS, $0 \%$ and $15 \%$ mean commercial sealant (Concise), ISDB sealant without filler and ISDB sealant with $15 \mathrm{wt} \%$ filler, respectively.

As a control group, commercially available dental sealant (Concise ${ }^{\mathrm{TM}}, \mathrm{CS}$ ), having $5 \sim 10 \mathrm{wt} \%$ filler, was selected. The depths of cure all reached over $1.5 \mathrm{~mm}$ and increased in the order $\mathrm{CS}=15 \%<10 \%<5 \%<1 \%<0 \%$ (Fig. 2A). Vickers hardness increased with increasing filler amount $(17.4 \pm 0.4 \sim 30.6 \pm 1.7 \mathrm{HV})$, and these values were significantly increased by $15 \%$ compared with their values of CS (Fig. 2B, P<0.05, versus $23.4 \pm 1.0 \mathrm{HV}$ ). The compressive strength and elastic modulus from $15 \%$ and CS samples showed comparable values $(91.3 \pm 16.6 \mathrm{MPa}$ versus $103.2 \pm 14.5 \mathrm{MPa}$ and $1.48 \pm 0.23 \mathrm{GPa}$ versus $1.43 \pm 0.15$ 
$1 \mathrm{GPa}$ at $\mathrm{P}>0.05$,), while these properties were both greater in the $15 \%$ sample compared to the

$20 \%$ sample (Fig. 2C, $\mathrm{P}<0.05$ ). The water solubility of $15 \%$ and $\mathrm{CS}$ samples was $\sim-0.006$ and

$3 \sim-0.002 \mu \mathrm{g} / \mathrm{mm}^{3}$, respectively, indicating little difference in solubility (Fig. 2D, increase in

4 weight for both materials). Water resorption was slightly increased in $0 \%$ and $15 \%$ samples

5 compared to the CS samples (Fig. 2D, $\mathrm{P}<0.05$ ) but below the maximum value for dental

6 restorative materials (40 $\mu \mathrm{g} / \mathrm{mm}^{3}$. ISO 4049). Lastly, flowability was measured using 20, 50,

7 and $75 \mu \mathrm{m}$ wide lines, revealing acceptable flowability to fill pits and fissures (Fig. 2E).

8 Scanning electron microscopy (SEM) images after 3 weeks of DW incubation at $37{ }^{\circ} \mathrm{C}$

9 showed a surface similarly roughened $(\sim 2$-fold $)$ to surfaces before incubation due to the

10 degradation of polymer in all groups, which was supported by parameters from roughening

11 analysis (Fig. 3A and $\mathbf{B}, \mathrm{Ra}, \mathrm{Ry}$, and Rz). 


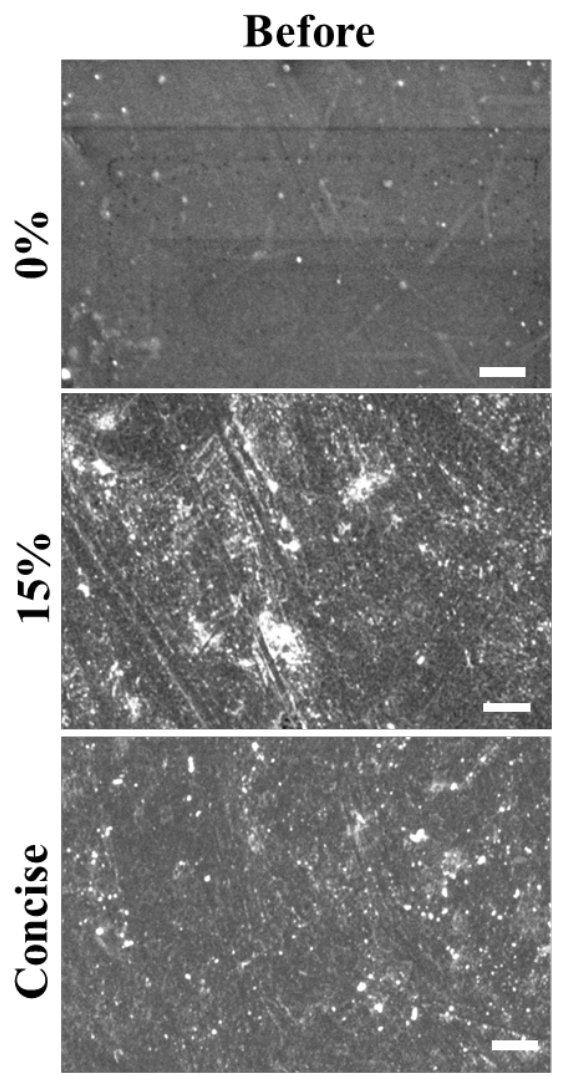

After 3 wks under DW
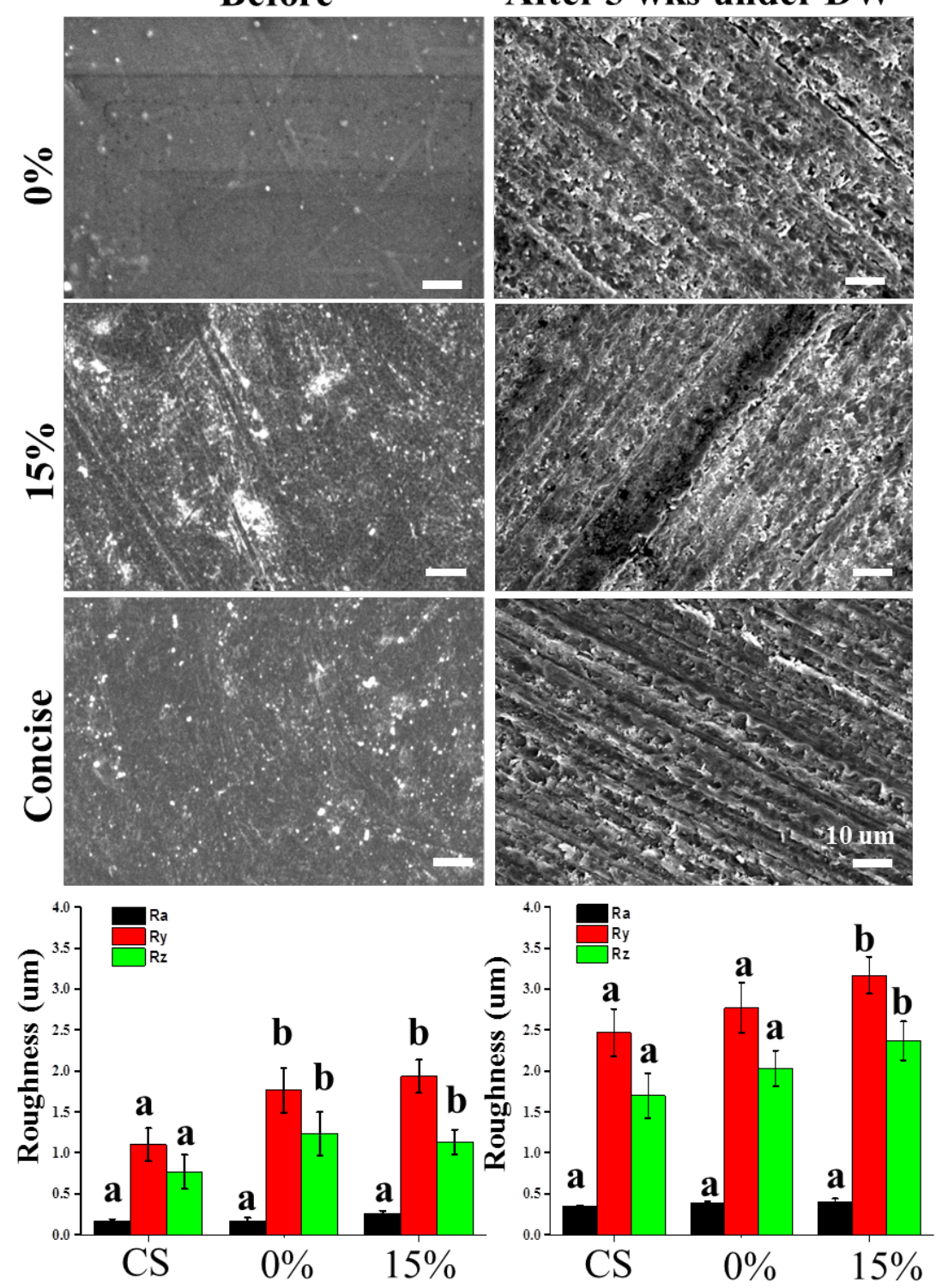

2 Figure 3. Surface morphology and roughness before and after incubation in distilled

3 water for 3 weeks. All experimental groups showed surfaces that had increased in roughness 4 ( two-fold) after long incubation times, as quantified by SEM images and roughness

5 analysis. CS, $0 \%$ and 15\% mean commercial sealant (Concise), ISDB sealant without filler 6 and ISDB sealant with $15 \mathrm{wt} \%$ filler, respectively. Different letters indicate statistically 7 significant differences between their corresponding values $(P<0.05)$.

\section{Cytocompatibility test}

The cell viability of oral keratinocytes, the major cell type in the outermost layer of oral 
1 mucosa, against 12.5 100\% extract was comparable among 0\%,15\% and CS samples (Fig.

$24 \mathbf{A}, P>0.05)$. This result was also visualized in images of live and dead cells with $100 \%$

3 extract (Fig. 4B), which showed similarly numbers of live cells in all groups compared to the

4 control, which was not treated with an extract.

5

6 Figure 4. Cytocompatibility of ISDB-based restorative materials with human oral

7 keratinocytes. Cytotoxicity test using extracts $\left(24 \mathrm{hr}\right.$ at $\left.37{ }^{\circ} \mathrm{C}\right)$ from specimens was

8 performed by (A) WST and (B) live (green) and dead (red, rarely detected due to detachment 9 of dead cells during washing) assays $(n=6)$. The \# sign indicates a statistically significant difference between the $100 \%$ extract and the control samples $(\mathrm{P}<0.05)$. Experimental groups exhibited comparable cytotoxicity.

\section{Estrogenicity}

In vitro estrogenicity was investigated with estrogen-sensitive MCF-7 cells. DNA synthesis of MCF-7 cells, measured by the BrdU assay, was not significantly increased among $0 \%, 15 \%$ and CS samples (Fig. 5, $P>0.05$ ), while positive controls (10 nM BPA and $100 \mathrm{nM}$ extradiol) showed an increase in DNA synthesis in MCF-7 cells $(P<0.05)$.
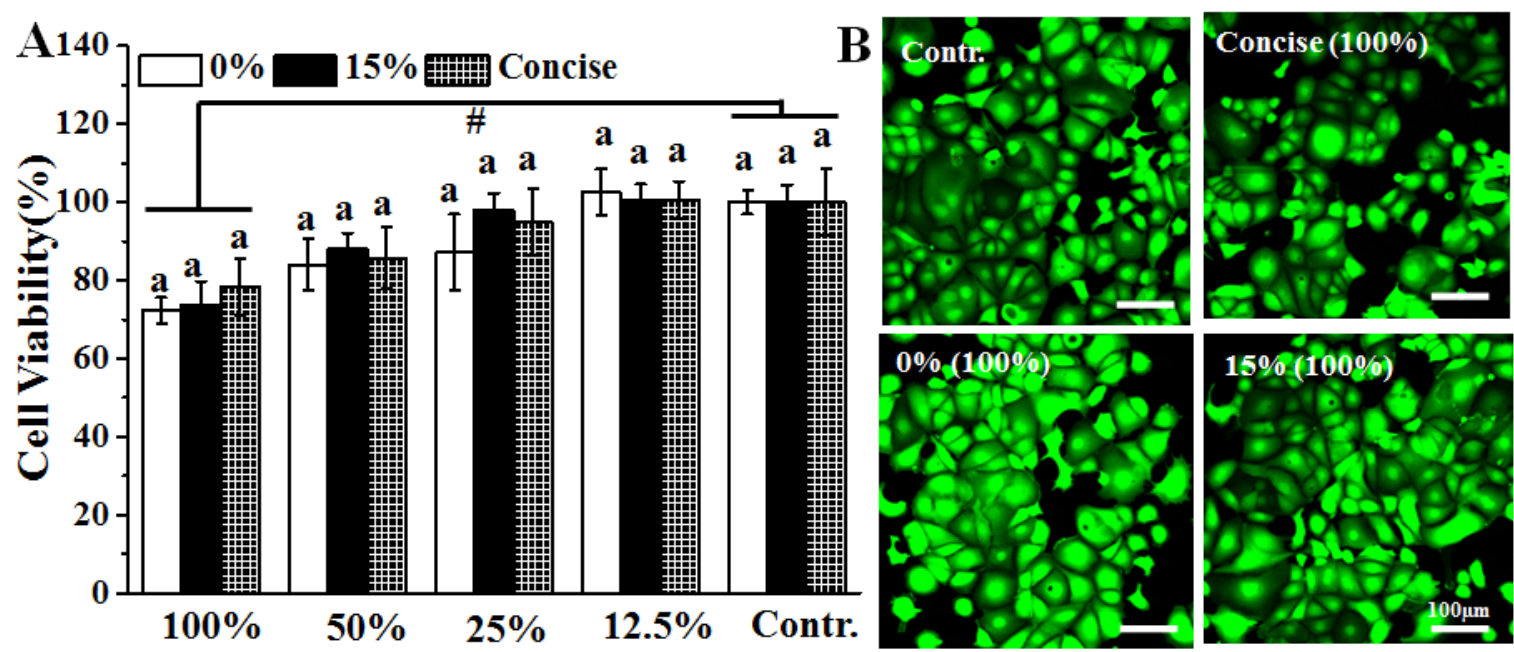


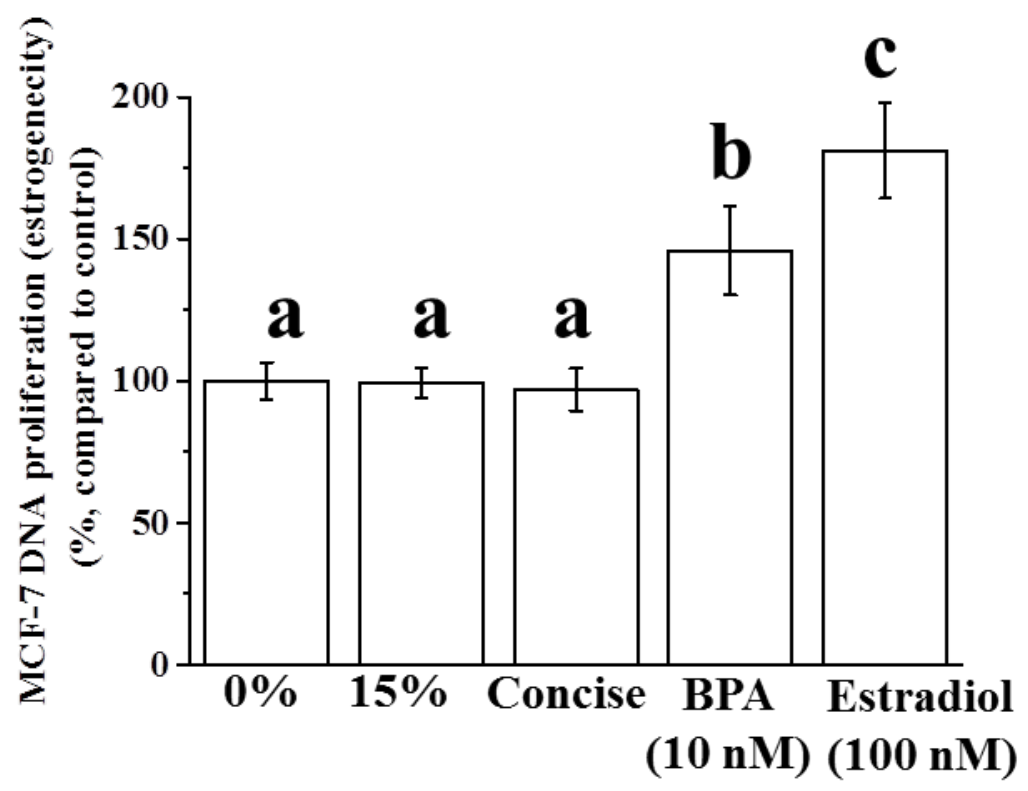

Figure 5. Results of the estrogenicity assay monitoring DNA synthesis for $24 \mathrm{hr}$ as an estrogen-mimicking action. Note the increased proliferation of positive groups (BPA and estradiol) relative to the control for estrogenicity-sensitive MCF-7 cells, which indicates an estrogen response. The estrogen response was not detected from $0 \%, 15 \%$ and Concise samples, revealing no estrogenicity.

\section{Discussion}

9 In the present study, we report the successful synthesis and characterization of ISDBs for use in medical device (i.e. dental restorative, medical implant, etc.). Among various medical devices, dental sealant from dental restorative materials is chosen due to their common use for children to prevent dental caries and many worries about estrogenicity from them. Here, ISDBs was utilized as a replacement of dental sealant, as a model, for oil-derived Bis-GMA to address the problem of estrogenicity. We synthesized ISDBs from isosorbide to produce $\mathrm{C}=\mathrm{C}$ bonds on both sides of the monomers for polymerization with other monomers such as TEGDMA via an addition reaction. Viscosity of ISDB (2.42 Pa.s) was 200 times less than that of Bis-GMA (473 $\mathrm{Pa} \cdot \mathrm{s})$ and 24 times higher than that of TEGDMA $(0.01 \mathrm{~Pa} \cdot \mathrm{s})$ under the same conditions, which possibily increase workability and adaptation of dental sealant on pit 
and fissure when ISDBs were adapted as major components [34]. ISDBs were utilized to

fabricate experimental dental sealant as a model of ISDB-based restorative dental material, and they were further supplemented with silanized micro-silica powder at levels up to $15 \mathrm{wt} \%$ to generate physico-mechanical properties comparable with those of a conventional dental sealant (i.e., CS). The optimized light curing time (40 s) was determined based on the $\mathrm{C}=\mathrm{C}$ $\left(1638 \mathrm{~cm}^{-1}\right)$ content decrease and depth of cure increase with increasing light curing time (not shown). The depth of cure, compressive strength, and water resorption/solubility were measured based on the ISO standards for polymer-based restorative materials. Although the standard of dental sealant required only depth of cure as a physico-chemical property, one of the basic parameters related to polymer-based restorative materials (water resorption/solubility) and the resistance to biting force (compressive strength) were chosen. The measured of depth of cure, water resorption/solubility and compressive strength values were comparable between $15 \%$ filler ISDB and CS samples, while Vickers hardness was $\sim 40 \%$ greater in $15 \%$ filler ISDB samples than in CS samples. To investigate in detail the surface degradation in the oral cavity, which is an indicator used to minimize plaque formation on the restorative surface and consequent initial/secondary dental caries, the specimen was incubated under DW for $21 \mathrm{~d}$ at body temperature $\left(37^{\circ} \mathrm{C}\right)$ with $100 \%$ humidity and dried at $60^{\circ} \mathrm{C}$ every day. The original smooth surface morphology increased in roughness $\sim 2$-fold in $0 \%$ and $15 \%$ filler ISDB and CS samples, revealing comparable surface degradation between ISDB-based restorative materials and commercial Bis-GMA-based materials and raising the possibility of cytotoxic or other biological concerns (estrogenicity) from degraded byproducts/monomers.

Similar to the commonly used Bis-GMA-based dental restorative materials, which are used due to their desired mechanical properties, the polymerization of ISDB-based composites is 
never complete, and thus unreacted monomers can remain after the curing process and induce adverse biological effects [7]. To investigate the initial adverse effects which may be strongly induced by release of unreacted monomers, a cytotoxicity test for human oral keratinocytes, a representative cell type in the outermost layers of the oral mucosa, was performed with the extracts; this test revealed comparable cytotoxicity between the commercial Bis-GMA-based dental material and the ISDB-based material.

Risks of safety issues arising after hydrolysis of the materials by enzymes (i.e., esterase) in the oral cavity remain. In the case of the Bis-GMA dental composite, hydrolysis occurs in vitro by saliva enzymes (i.e., esterase) at its ester bond $(\mathrm{O}=\mathrm{C}-\mathrm{O})$, and byproducts such as BisGMA without 1 2 methacrylic acid groups were released without estrogenic BPA [35], indicating a low possibility of estrogenicity [7]. However, health concerns might arise with respect to Bis-GMA-derived degradation products, since they all contain the BPA moiety, and in vivo conditions might accelerate hydrolytic degradation to less reactive ether bonds (C-O-C), which is supported by clinical investigations with high concentrations of BPA in saliva from dental sealant-treated children [8,9,36,37]. To tackle this BPA-induced estrogenicity, we designed a BPA-free ISDB-based dental material. As designed, when degradation of the ISDB-based dental restorative materials was tested with esterase to mimic hydrolytic degradation activity in the oral cavity, only the isosorbide derivate (isosorbideethylene glycol) without a BPA moiety was detected; this derivate has not been identified as a strongly toxic compound or an estrogenicity inducer so far, which was confirmed by no estrogenic response from ISDBs dental sealant in current in vitro study. The estrogen response was not either detected for Concise samples, meaning that fully polymerized BisGMA based dental materails can't generate estrogenic response under in vitro condition [38]. According to other literatures, ISDB-based biopolymers have been considered to generate a 
noncytotoxic and non-inflammatory response compared to the culture-grade polystyrene control [13,39]. Even though the estrogenicity of isosorbide-based biopolymers and their derivatives have not been reported until now, further study investigating the safe use of ISDBs in dental restorative materials is necessary for clinical application.

In summary, ISDB-based biopolymers are highlighted as possible replacement biomonomers due to their safe origin, biocompatibility, comparable physico-mechanical properties and lack of estrogenicity compared to petrochemically derived Bis-GMA materials [12,18]. Along with the above benefits reported in the current investigation and the literature, this study describes the first trial utilizing ISDBs in dental restorative materials.

In conclusion, this study is the first to demonstrate the synthesis of ISDBs and their possible utilization in dental restorative materials. Within the limitations of this study, ISDBs had physico-chemical and biological characteristics comparable to those of commercial BisGMA-based restorative materials. With the design of a BPA-free polymer structure/network and results from in vitro degradation and estrogenicity tests to confirm the absence of BPA as a hydrolytic byproduct and its consequent estrogenicity, ISDB can be used in dental restorative materials and further studied in in vivo biocompatibility tests and clinical trials.

\section{Author contributions}

SK Jun contributed to the conception and design of the study, specimen preparation, and data acquisition (mechanical properties), analysis (mechanical properties), and interpretation; JRCha contributed to the conception and design of the study and data acquisition (biopolymer), analysis (biopolymer), and interpretation; HW Kim and JC Knowles contributed to material, biological and data analysis and critically revised the manuscript; and JH Lee and HH Lee equally contributed to the conception and design of the study, data analysis and interpretation, 
1 and critical revision of the manuscript. All authors have approved and agreed to be 2 accountable for all aspects of this work.

3

\section{Acknowledgements}

5 This work was supported by a National Research Foundation of Korea (NRF) grant funded 6 by the Ministry of Science and ICT (2018R1D1A1B07042920, 2019R1C1C1002490, the

7 Global Research Development Center Program (2018K1A4A3A01064257)) and by the

8 Ministry of Education (Priority Research Center Program (2019R1A6A1A11034536)). In

9 addition, this work was supported by the University Innovation Support Program through the

10 National Research Foundation of Korea (NRF) funded by the Ministry of Education 11 (Dankook University 2019). 


\section{References}

[1] Kinch CD, Ibhazehiebo K, Jeong J-H, Habibi HR, Kurrasch DM. Low-dose exposure to bisphenol $\mathrm{A}$ and replacement bisphenol $\mathrm{S}$ induces precocious hypothalamic neurogenesis in embryonic zebrafish. Proc Natl Acad Sci U S A 2015;112:1475-80.

[2] Braun JM, Yolton K, Dietrich KN, Hornung R, Ye X, Calafat AM, et al. Prenatal bisphenol A exposure and early childhood behavior. Environ Health Perspect 2009;117:1945.

[3] Monteleone P, Mascagni G, Giannini A, Genazzani AR, Simoncini T. Symptoms of menopause - global prevalence, physiology and implications. Nat Rev Endocrinol 2018;14:199.

[4] Ferracane JL. Models of Caries Formation around Dental Composite Restorations. J Dent Res 2017;96:364-71.

[5] Li Y, Burns KA, Arao Y, Luh CJ, Korach KS. Differential estrogenic actions of endocrine-disrupting chemicals bisphenol A, bisphenol AF, and zearalenone through estrogen receptor $\alpha$ and $\beta$ in vitro. Environ Health Perspect 2012;120:1029.

[6] Zhang Z, Hu Y, Guo J, Yu T, Sun L, Xiao X, et al. Fluorene-9-bisphenol is antioestrogenic and may cause adverse pregnancy outcomes in mice. Nat Commun $2017 ; 8: 14585$.

[7] Ferracane JL. Hygroscopic and hydrolytic effects in dental polymer networks. Dent Mater 2006;22:211-22.

[8] Manoj MK, Ramakrishnan R, Babjee S, Nasim R. High-performance liquid chromatography analysis of salivary bisphenol A levels from light-cured and chemically cured orthodontic adhesives. Am J Orthod Dentofacial Orthop $2018 ; 154: 803-8$. 
1 [9] Berge TLL, Lygre GB, Jönsson BAG, Lindh $\mathrm{CH}$, Björkman L. Bisphenol A concentration in human saliva related to dental polymer-based fillings. Clin Oral Investig 2017;21:2561-8.

[10] Koin P, Kilislioglu A, Zhou M, Drummond J, Hanley L. Analysis of the degradation of a model dental composite. J Dent Res 2008;87:661-5.

[11] Nelson AM, Long TE. A perspective on emerging polymer technologies for bisphenol-A replacement. Polym Int 2012;61:1485-91.

[12] Fenouillot F, Rousseau A, Colomines G, Saint-Loup R, Pascault JP. Polymers from renewable 1,4:3,6-dianhydrohexitols (isosorbide, isomannide and isoidide): A review. Prog Polym Sci 2010;35:578-622.

[13] Hong J, Radojčić D, Ionescu M, Petrović ZS, Eastwood E. Advanced materials from corn: isosorbide-based epoxy resins. Polym Chem 2014;5:5360-8.

[14] Joo Y-S, Cha J-R, Gong M-S. Biodegradable shape-memory polymers using polycaprolactone and isosorbide based polyurethane blends. Materials Science and Engineering: C 2018;91:426-35.

[15] Łukaszczyk J, Janicki B, López A, Skołucka K, Wojdyła H, Persson C, et al. Novel injectable biomaterials for bone augmentation based on isosorbide dimethacrylic monomers. Materials Science and Engineering: C 2014;40:76-84.

[16] Śmiga-Matuszowicz M, Janicki B, Jaszcz K, Łukaszczyk J, Kaczmarek M, Lesiak M, et al. Novel bioactive polyester scaffolds prepared from unsaturated resins based on isosorbide and succinic acid. Materials Science and Engineering: C 2014;45:64-71.

[17] Śmiga-Matuszowicz M, Korytkowska-Wałach A, Nowak B, Pilawka R, Lesiak M, Sieroń AL. Poly(isosorbide succinate)-based in situ forming implants as potential systems for local drug delivery: Preliminary studies. Materials Science and 
Engineering: C 2018;91:311-7.

[18] Galbis JA, García-Martín MdG, de Paz MV, Galbis E. Synthetic polymers from sugarbased monomers. Chem Rev 2015;116:1600-36.

[19] Feng X, East AJ, Hammond WB, Zhang Y, Jaffe M. Overview of advances in sugarbased polymers. Polym Adv Technol 2011;22:139-50.

[20] ISO 4049. Polymer-based restorative materials. Switzerland: International Standardization Organization; 2009.

[21] ISO 6874. Polymer-based pit and fissure sealants. Switzerland: International Standardization Organization; 2015.

[22] ISO 9917-1. Water-based cements - part 1: powder/liquid acid-base cements. Switzerland: International Standardization Organization; 2007.

[23] Lee HH, Lee CJ, Asaoka K. Correlation in the mechanical properties of acrylic denture base resins. Dent Mater J 2012;31:157-64.

[24] Lee J-H, Jo J-K, Kim D-A, Patel KD, Kim H-W, Lee H-H. Nano-graphene oxide incorporated into PMMA resin to prevent microbial adhesion. Dent Mater 2018;34:e63-e72.

[25] Kang MS, Lee N-H, Singh RK, Mandakhbayar N, Perez RA, Lee J-H, et al. Nanocements produced from mesoporous bioactive glass nanoparticles. Biomaterials 2018;162:183-99.

[26] Lee J-H, Lee M, Kim K-N, Hwang C-J. Resin bonding of metal brackets to glazed zirconia with a porcelain primer. Korean J Orthod 2015;45:299-307.

[27] Lee H-J, Guo H-Y, Lee S-K, Jeon B-H, Jun C-D, Lee S-K, et al. Effects of nicotine on proliferation, cell cycle, and differentiation in immortalized and malignant oral keratinocytes. J Oral Pathol Med 2005;34:436-43. 
1 [28] ISO 10993-5. Biological evaluation of medical devices - part 5: tests for in vitro cytotoxicity. Switzerland: International Standardization Organization; 2009.

[29] ISO 10993-12 Biological evaluation of medical devices - Part 12: Sample preparation and reference materials: ISO; 2012.

[30] Lee J-H, Lee H-H, Kim K-N, Kim K-M. Cytotoxicity and anti-inflammatory effects of zinc ions and eugenol during setting of ZOE in immortalized human oral keratinocytes grown as three-dimensional spheroids. Dent Mater 2016;32:e93-e104.

[31] Resende FA, de Oliveira APS, de Camargo MS, Vilegas W, Varanda EA. Evaluation of estrogenic potential of flavonoids using a recombinant yeast strain and MCF7/BUS cell proliferation assay. PLoS One 2013;8:e74881.

[32] Lee ST, Oh SW, Kim DY, Han JY, Moon SY, Lim JM. Serum replacement with a growth factor-free synthetic substance in culture medium contributes to effective establishment of mouse embryonic stem cells of various origins. Fertil Steril 2006;86:1137-45.

[33] Pathak VM. Review on the current status of polymer degradation: a microbial approach. Bioresour Bioprocess 2017;4:15.

[34] Habib E, Wang R, Zhu XX. Correlation of resin viscosity and monomer conversion to filler particle size in dental composites. Dent Mater 2018;34:1501-8.

[35] Wada H, Tarumi H, Imazato S, Narimatsu M, Ebisu S. In vitro estrogenicity of resin composites. J Dent Res 2004;83:222-6.

[36] Han D-H, Kim M-J, Jun E-J, Kim J-B. Salivary bisphenol-A levels due to dental sealant/resin: a case-control study in Korean children. J Korean Med Sci 2012;27:1098-104.

[37] Zimmerman-Downs JM, Shuman D, Stull SC, Ratzlaff RE. Bisphenol A blood and 
saliva levels prior to and after dental sealant placement in adults. J Dent Hyg 2010;84:145-50.

3 [38] Gupta SK, Saxena P, Pant VA, Pant AB. Release and toxicity of dental resin composite. Toxicol Int 2012;19:225-34.

5 [39] Gogolewski S, Gorna K, Zaczynska E, Czarny A. Structure-property relations and cytotoxicity of isosorbide-based biodegradable polyurethane scaffolds for tissue repair and regeneration. J Biomed Mater Res A 2008;85A:456-65.

8 
$1 \quad$ Appendix

2

3 sTable 1. Summary of NMR analysis from BHIS and ISDB

\begin{tabular}{|c|c|c|c|c|c|c|}
\hline \multirow[t]{2}{*}{ Compound } & \multirow{2}{*}{$\begin{array}{c}\text { Mass spectra } \\
\text { positive ion mode } \\
(\text { found })[\mathrm{M}]^{+\cdot}\end{array}$} & \multicolumn{4}{|c|}{$\begin{array}{l}\text { EA calculated } \\
\text { (found }), \%\end{array}$} & \multirow{2}{*}{$\begin{array}{c}{ }^{1} \mathrm{H} \mathrm{NMR}\left(\mathrm{CDCl}_{3}\right) \\
\delta(\mathrm{ppm})\end{array}$} \\
\hline & & $\mathrm{C}$ & $\mathrm{H}$ & $\mathrm{N}$ & $\mathrm{O}$ & \\
\hline $\begin{array}{c}\text { BHIS } \\
\left(\mathrm{C}_{10} \mathrm{H}_{18} \mathrm{O}_{6}\right)\end{array}$ & 234.11 & 48.43 & 7.83 & - & 43.68 & $\begin{array}{c}\text { 2.00-3.40 (s, 2H hydroxy) } \\
\text { 3.57-3.73 (m, 8H, ethyl) } \\
\text { 3.85-4.07 (m, 4H, isosorbide) } \\
\text { 4.54-4.74 (m, 4H, isosorbide) }\end{array}$ \\
\hline $\begin{array}{c}\text { ISDB } \\
\left(\mathrm{C}_{24} \mathrm{H}_{36} \mathrm{~N}_{2} \mathrm{O}_{12}\right)\end{array}$ & 544.55 & 52.73 & 6.88 & 5.17 & 35.28 & $\begin{array}{c}1.95(\mathrm{~s}, 6 \mathrm{H} \text { methyl }) \\
3.51(\mathrm{~s}, 4 \mathrm{H} \text { ethyl }) \\
3.60-3.67(\mathrm{~m}, 6 \mathrm{H} \text { ethyl }) \\
3,87-4.05(\mathrm{~m}, 6 \mathrm{H} \text { isosorbide }) \\
4.24(\mathrm{~s}, 6 \mathrm{H} \text { ethyl }) \\
4.50-4.64(\mathrm{~m}, 2 \mathrm{H} \text { isosorbide }) \\
5.1(\mathrm{~s}, 2 \mathrm{H} \text { amine }) \\
5.60(\mathrm{~s}, 2 \mathrm{H} \text { acryl }) \\
6.12(\mathrm{~s}, 2 \mathrm{H} \text { acryl })\end{array}$ \\
\hline
\end{tabular}




\section{A. BHIS (intermediate product)}

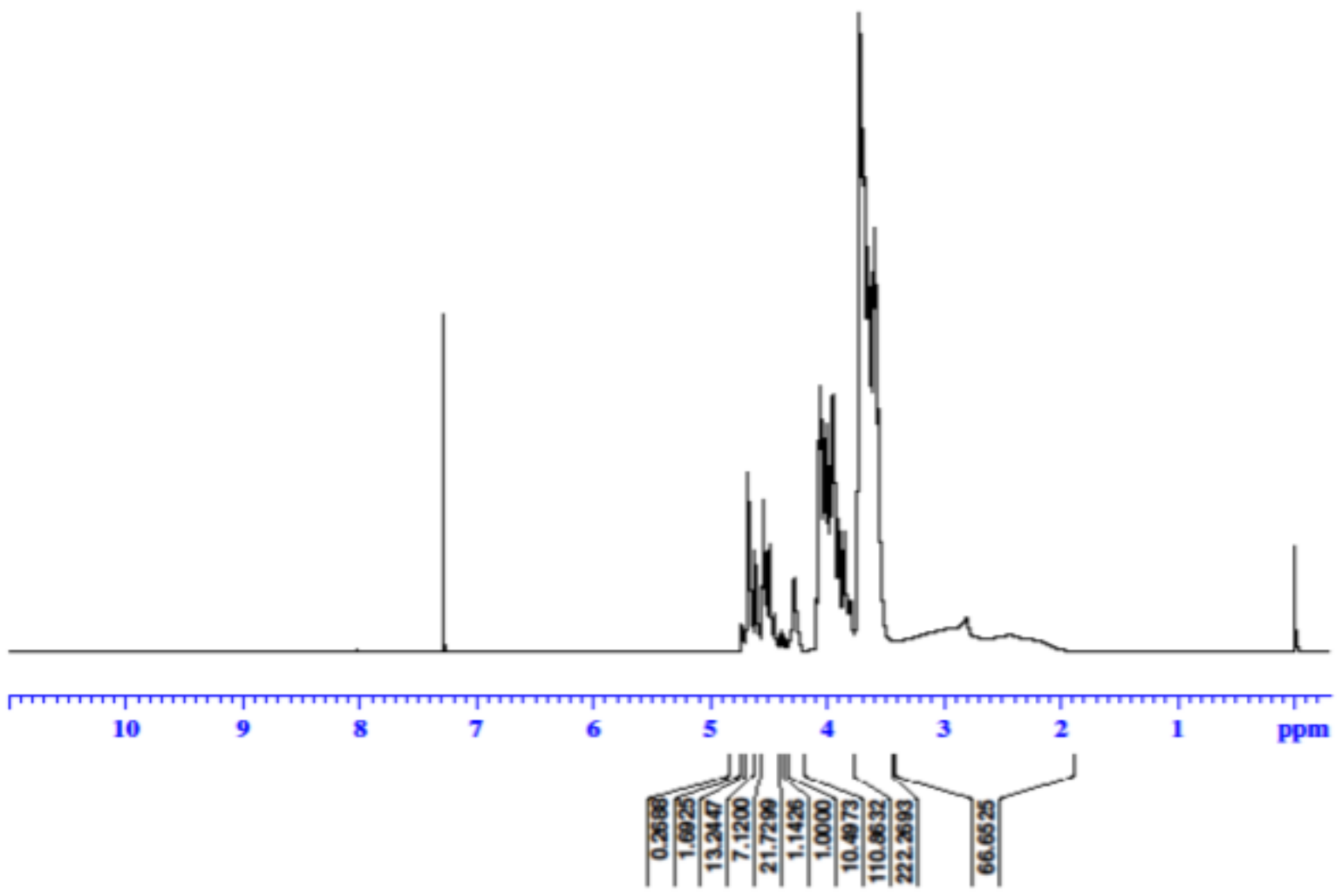

1-IS \#3799 RT: $12.77 \quad$ AV: 1 SB: $212.82,12.64$ NL: $2.89 E 8$

T: + c El Full ms [50.000-700.000]

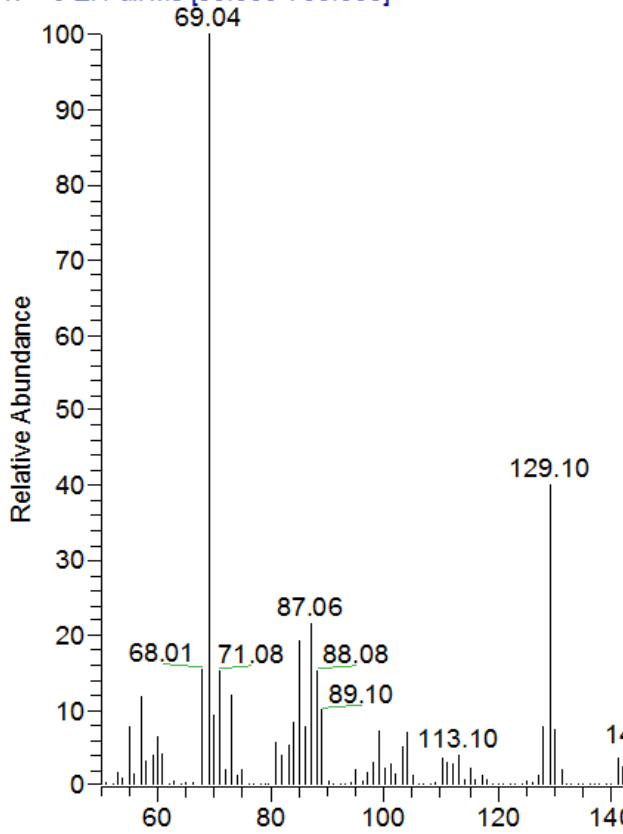

sFig. 1 continued 


\section{B. SCDB (final monomer)}

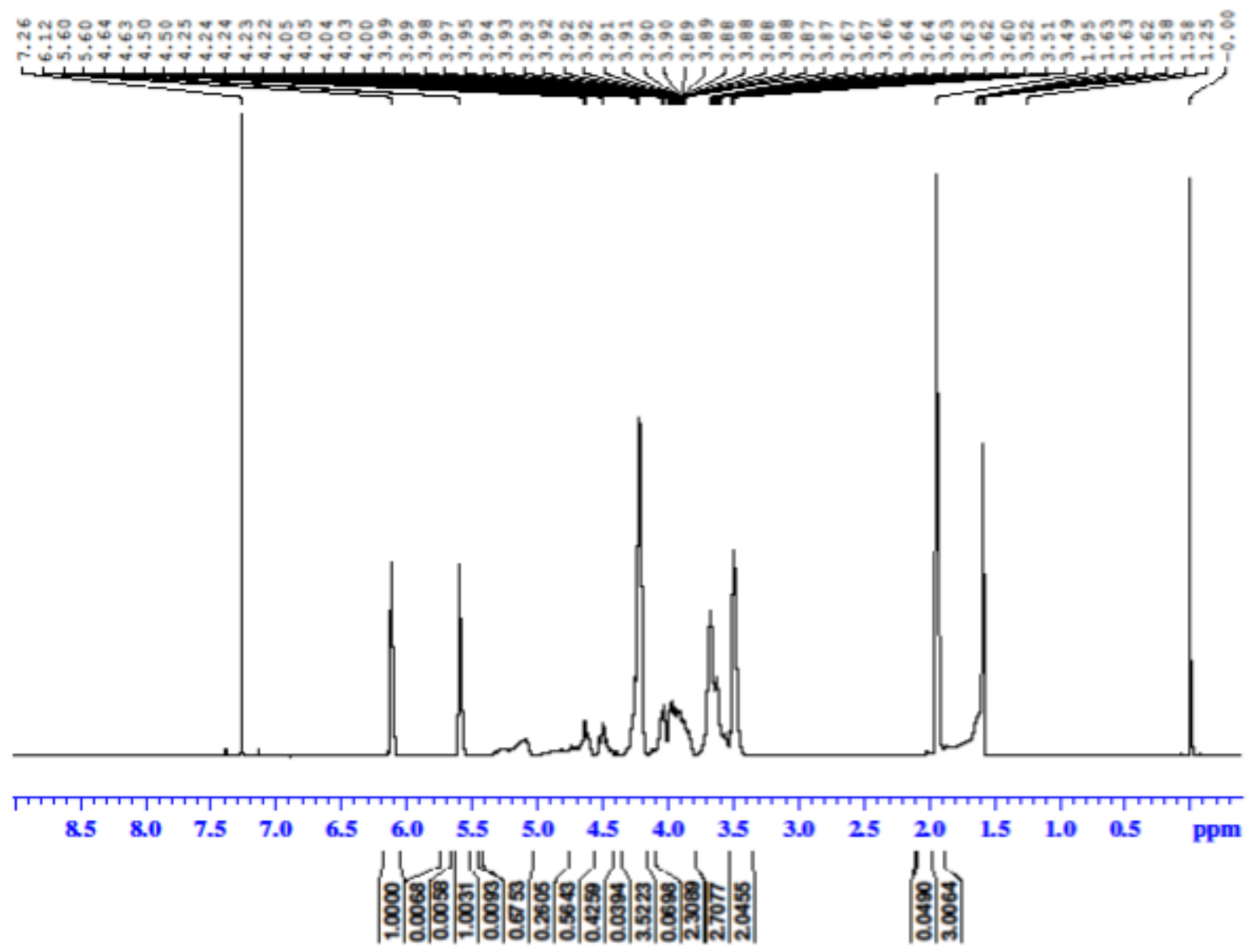

W-15 $180808132750 \# 5179$ RT: 17.40 AV: 1 SB: 2 17.54, 17.35 NL: 2.63E5

$\mathrm{T}:+\mathrm{c}$ El Full ms [50.000-700.000]

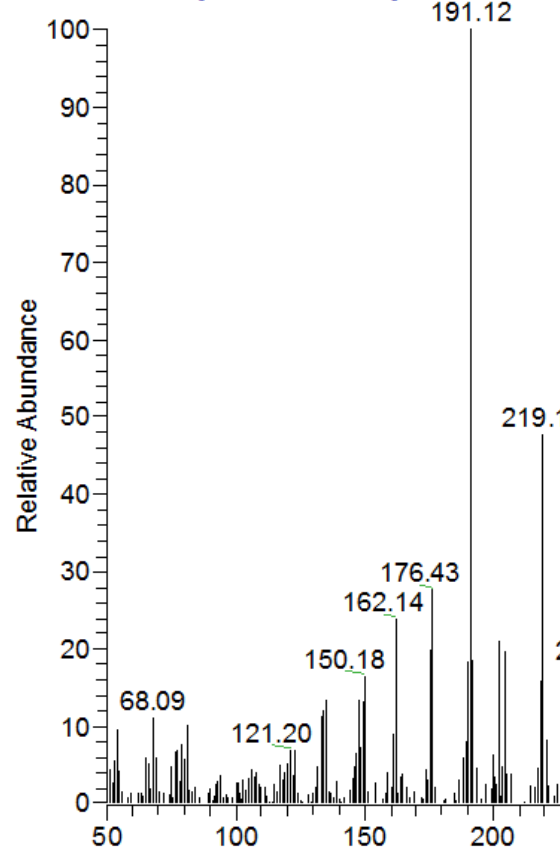

261.16

232.17

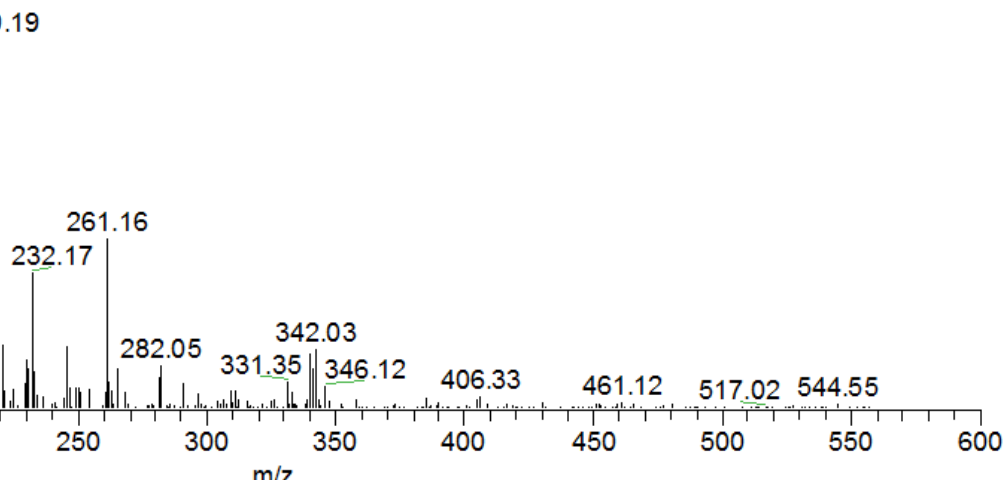

sFig. 1 continued 


\section{Element analysis and designed chemical formula} Sample name Nitrogen

BHIS

n.d. Carbon

ISDB

5.1731

48.4326 Hydrogen

Oxygen

7.8312

43.6757

2

BHIS

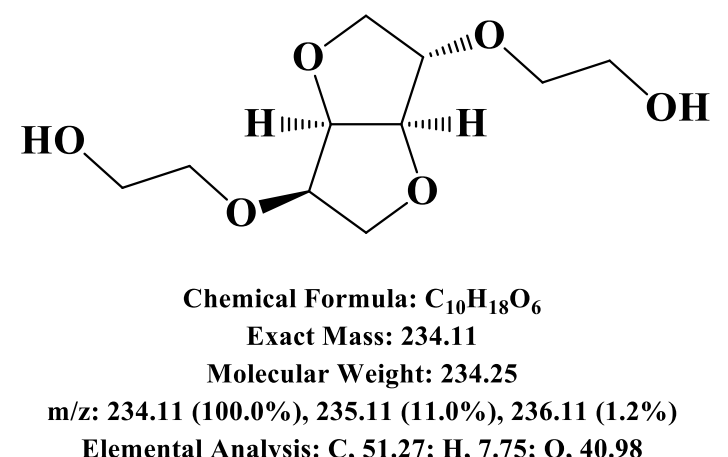

CSMA

Elemental Analysis: C, 51.27; H, 7.75; O, 40.98<smiles>C=C(C)C(=O)OCCNC(=O)OCCO[C@H]1CO[C@@H]2[C@@H](OCCOC(=O)NCCOC(=O)C(=C)C)CO[C@@H]12</smiles>

Chemical Formula: $\mathrm{C}_{24} \mathrm{H}_{36} \mathrm{~N}_{2} \mathrm{O}_{12}$

Exact Mass: 544.23

Molecular Weight: $\mathbf{5 4 4 . 5 5}$

$\mathrm{m} / \mathrm{z}: 544.23(100.0 \%), 545.23(26.8 \%), 546.23$ (6.0\%)

sFig. 1 Fabrication of (A) BHIS and (B) Bis-GMA-free monomer (ISDB) and their characterization by NMR (up) \& GC/MS (down). (C) Analysed element of each product and 6 their designated chemical formula. 


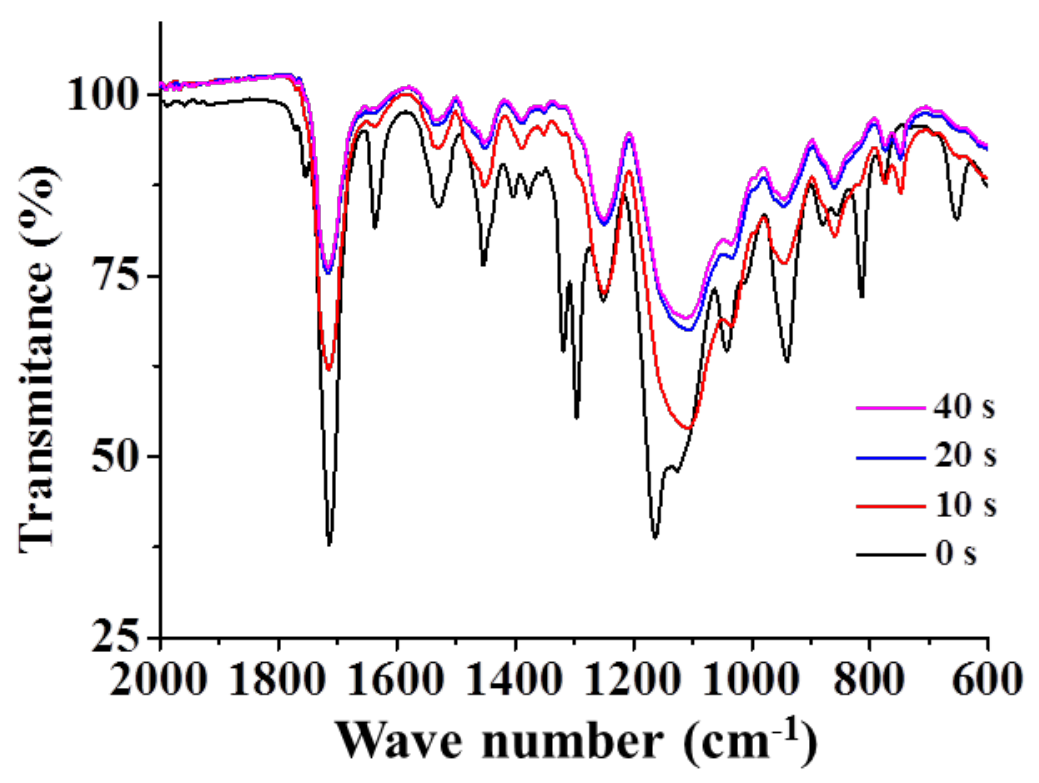

1

2 sFig. 2 FT-IR spectra of ISDB-based sealant vs. light curing time 3 
$1 \mathbf{A}$

RT: $2.00-15.00$

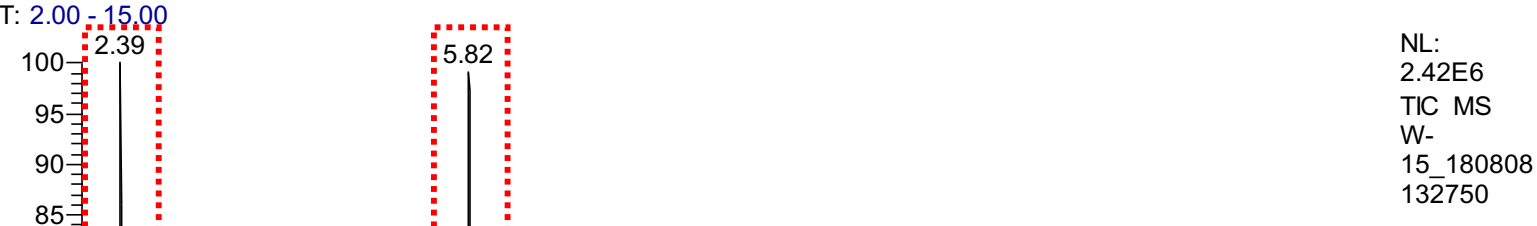

2

B W-15_180808132750 \#701 RT: 2.38 AV: 1 SE

T: + c El Full ms [50.000-700.000]

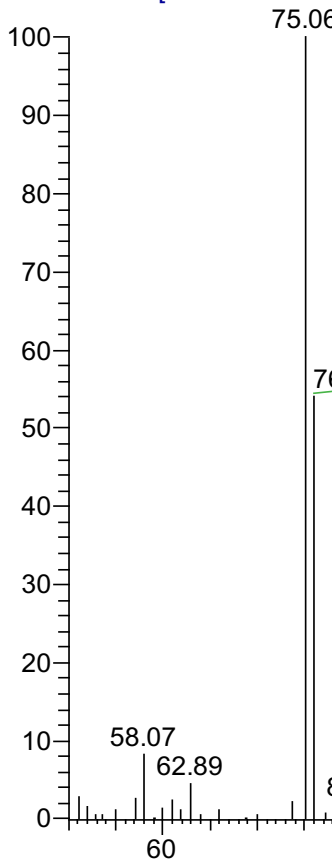

3, 2.22 NL: 2.71E5

5.06

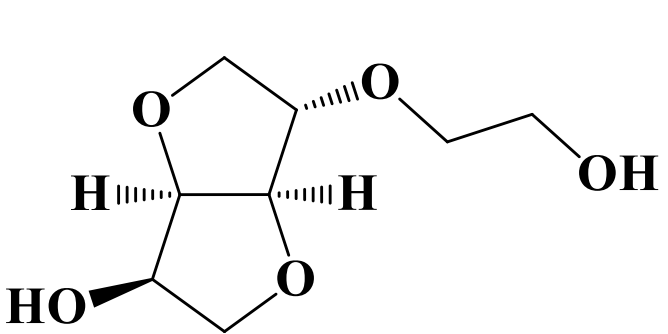

Chemical Formula: $\mathrm{C}_{8} \mathrm{H}_{14} \mathrm{O}_{5}$

Exact Mass: 190.08

Molecular Weight: 190.19

m/z: 190.08 (100.0\%), 191.09 (9.0\%), 192.09 (1.4\%)

Elemental Analysis: C, 50.52; H, 7.42; O, 42.06

sFig. 3 continued 
C

W-15_180808132750\#1727 RT: 5.82 AV: 1 S

T: + c El Full ms [50.000-700.000]

100

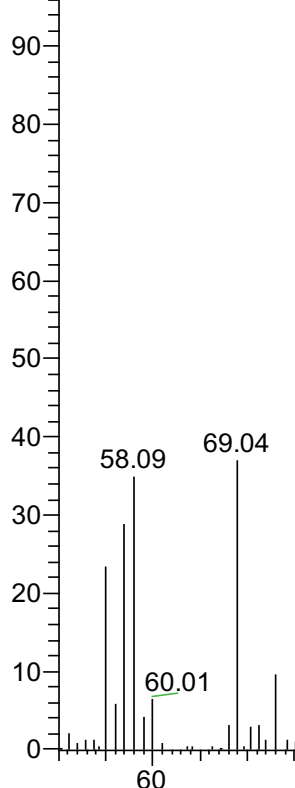

86.08

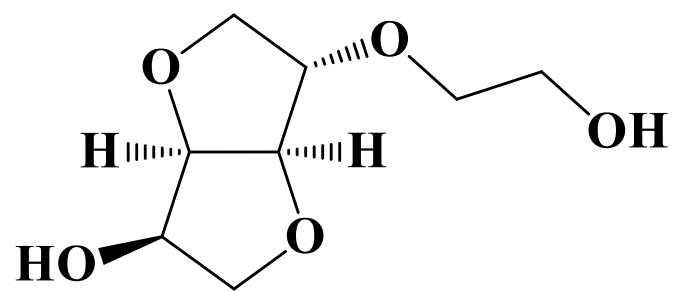

Chemical Formula: $\mathrm{C}_{8} \mathrm{H}_{14} \mathrm{O}_{5}$ Exact Mass: 190.08

Molecular Weight: 190.19

m/z: 190.08 (100.0\%), 191.09 (9.0\%), 192.09 (1.4\%)

Elemental Analysis: C, 50.52; H, 7.42; O, 42.06

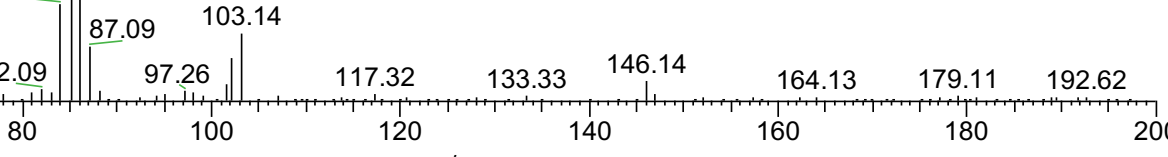

3 $\mathrm{m} / \mathrm{z}$

4 sFig. 3. GC/MS spectra and retention times of ISDB degraded by esterase: (A) full-scan 5 spectrum, (B) spectrum at $2.39 \mathrm{~min},(\mathrm{C})$ spectrum at $5.82 \mathrm{~min}$. 